\title{
Efficiency of direct saponification for the analysis of $n$-alkanes in hays
}

\author{
R Ferrer, M Petit, G Béchet
}

INRA, Laboratoire Adaptation des Herbivores aux Milieux, Theix, 63122 Saint-Genès-Champanelle, France

The use of alkanes as forage markers for digestive studies requires efficient and rapid methods of extraction and analysis. From the results of Dillon and Stakelum (1990), direction saponification (DS) of grass and faecal samples gives similar results to those given by the method using prior extraction by the Sox/het method before saponification ( $\mathrm{Sx}$ ) as described by Mayes et al (1986).

Three meadow hays were analysed by methods DS and $S x$, with 4 samples (from 4 different bales) per hay and extractions in duplicate. Alkanes were quantified by gas chromatography using C34 as internal standard in both cases; a semi-capillary column was used. Odd-alkanes (from $\mathrm{C} 27$ to $\mathrm{C35}$ ) were only considered because of their abundance in grass forages and because C31 and C33 are the most useful internal markers (Mayes et al, 1986). The results were analysed by the least-squares procedure (SAS, 1988) with fixed effects of method and hay, method $x$ hay interaction and samples (nested in hay).

The DS method gave higher values than the Sx method for C27, C29 and C31 (see table I). No difference was noted for C33 and C35. Large variations (with a range from 1 to 4 ) in alkane contents were observed between hays according to cutting area and between bales of hay, the coefficient of variation (CV) amounting to $31 \%$ for C31 and $28 \%$ for C33.
However, significant interaction was observed between both methods and hays, especially for C27, C29 and C31. For all the alkanes analysed (except C35), the DS method was more efficient for 1 hay which displayed the higher alkane content.

Residual CV was the lowest for C33 (6\%) (table I), indicating optimum repeatability of analysis. In addition, differences between duplicates were lower and less variable between samples with DS than with Sx from $\mathrm{C} 27$ to $\mathrm{C} 31$ (C31: $9 \pm 7 \%$ vs $13 \pm 15 \%)$ and similar for $C 33(9 \pm 9 \%$ vs $8 \pm 8 \%)$.

In conclusion, analysis of odd-alkanes $\mathrm{C} 27$ to C31 from hay samples needs direct saponification, which gives higher values with better repeatability than the similar method using prior extraction by the Soxlhet method. Both methods give similar results for $\mathrm{C} 33$, which is the most frequently used alkane when its content in forages is sufficient.

The high variability of alkane contents between bales of the same hay highlights the difficulties encountered in using alkanes as markers of complex forages.

Dillon P, Stakelum G (1990) Proc VII Eur Grazing Workshop (Wageningen, The Netherlands)

Mayes RW, Mamb CS, Colgrove PM (1986) $J$ Agric Sci Camb 107, 161-170

Table I. Effect of method of extraction of odd-alkanes on their contents in hays.

\begin{tabular}{lccccc}
\hline Alkane & C27 & C29 & C31 & C33 & C35 \\
\hline Soxlhet + saponification & 43.7 & 240 & 304 & 87.6 & 10.3 \\
Direct saponification & 75.7 & 348 & 347 & 86.7 & 9.8 \\
$\begin{array}{l}\text { Significance of effects: } \\
\text { Method }\end{array}$ & $* * *$ & $* * *$ & $* *$ & NS & NS \\
$\begin{array}{l}\text { Hay } \\
\text { Method x hay }\end{array}$ & $* * * *$ & $* * *$ & $* * *$ & $* * *$ & $*$ \\
Residual SD & 15.5 & 63.1 & 32.7 & 5.1 & 1.3 \\
\hline
\end{tabular}

Significance: ${ }^{*} P<0.05 ; * * P<0.01 ;{ }^{* *} P<0.01$. 